\title{
NATURAL INFRASTRUCTURE CONCEPT IN ARID REGIONS: TWO CASE STUDIES IN EGYPTIAN CONTEXT
}

\author{
N. MAHMOUD ${ }^{1} \&$ P. SELMAN ${ }^{2}$ \\ ${ }^{1}$ Urban Design Department, Faculty of Urban and Regional Planning, Cairo University, Egypt. \\ ${ }^{2}$ Department of Landscape, University of Sheffield, UK.
}

\begin{abstract}
The term 'green infrastructure' in arid areas may not be 'green' as a colour. It is used as a metaphor to improve the cultural, historic and social values in these areas. Thus, natural infrastructure (NI) as a whole term and green infrastructure as a specific and common concept are classified as valuable infrastructure in Middle Eastern countries, particularly Egypt, possibly because in arid areas there is relatively little landscape that is naturally green with a small amount of rainfall. Additionally, the social and cultural resources are considered as the basic factors of green and blue infrastructure in arid zones because the nature of people who live in arid areas is different from others. This paper outlines the concept of NI in the Egyptian context via two different case studies, each of which has its own aspects, in terms of spatial planning strategies. There have been specific features that highlight and draw the main theme of each case. These features are related to specific criteria, such as location, scale, urban features and associated activities. The first case is about the natural connectivity along the River Nile that naturally links the three biggest islands and connects different urban communities. The second case is the ecological connection of a green network within the urban district of Maadi and the natural, environmental and historic protected area of Wadi Degla. These main two areas represent the natural, cultural activities and biodiversity. This article, therefore, analyses these cases by using IKONOS GIS maps of Greater Cairo. These maps have been based on the official documentations, from site visits and through conducting interviews with specialists who have responsibilities for spatial planning either in academic or professional sectors in Egypt.

Keywords: connectivity, cultural and historic values, ecological corridor, environmental landscape projects, green corridor, green infrastructure, irrigation system, multi-functionality, natural infrastructure, planning strategy, social sustainability, spatial planning, sustainable landscape.
\end{abstract}

\section{INTRODUCTION}

The term natural infrastructure (NI) cannot be taken as a separate term for green infrastructure (GI), because the NI has both green and blue infrastructures. The blue infrastructure is related to water features such as rivers, streams, canals and tributaries. The terminology green infrastructure is more popular, particularly in European countries, which refer to green elements of green colour. However, in this context, this paper's viewpoint will not use GI to mean its greeny aspect but to mean its valuable ones. Yet, as Lyle [1] noted, 'If we can understand nature's evolved responses and adaptations to conditions of aridity and if we can observe and comprehend the landscape forms that derive from those adaptations, then we might use these as basic archetypes for arid and semi-arid regions'.

Therefore, this paper focuses on two case studies, located geographically in the Greater Cairo Region, but different in their planning characteristics. Abdelhalim [2] explained the relation between the culture of Cairo and its urban production, especially the culture and behaviour of the local community in Egypt and environmental landscape projects. He emphasized the importance of culture that is considered to be the prime mechanism for creating and maintaining natural and environmental landscape projects. Importantly, the aspect that affects NI in arid areas is the irrigation system via available water sources. Bashandy [3] focused on the historical establishment 
of greenways and green networks system from the beginning of the 20th century in Cairo. This beginning helped Cairo to be a habitable and sustainable city within special morphological studies. Additionally, the greenway is considered to be a connector between the public open spaces network and pedestrian paths. This network is based on the River Nile and its conduits as the main source of irrigation system in Egypt.

In this respect, the analysis of these cases is based on three major criteria: connectivity, multifunctionality (MF) and sociocultural sustainability. Then, from each case, the conclusions will be compared with each other to determine the suitable criteria or recommendations for developing or creating NI in arid climates in general, and Cairo in particular.

\section{NATURAL INFRASTRUCTURE MECHANISM}

The aim of the mechanism is to build the structure 'protocol' that allows the application of different concepts, ideas, designs and plans to be established, which will be more beneficial for local people (Fig. 1). Many planners and designers consider the GI planning layer as a separate layer and do not include it in a wider scope of environmental master plans. In particular, GI is considered as a new field in Middle Eastern countries such as Egypt. Therefore, the GI layer should participate in other master plans, such as social, economic, recreational and visual activities in the planning process, because it forms the fundamental factor of environmental sustainable planning. Thus, the planning strategies would be derived from the management and implementation phase. Benedict and McMahon [4] reported that: 'Green infrastructure should be carefully planned, designed and expanded as communities grow. Green infrastructure planning should be the first step in developing land use plans, and should be coordinated with planning roads, sewers, water lines; and other essential gray infrastructure' (p. 15).

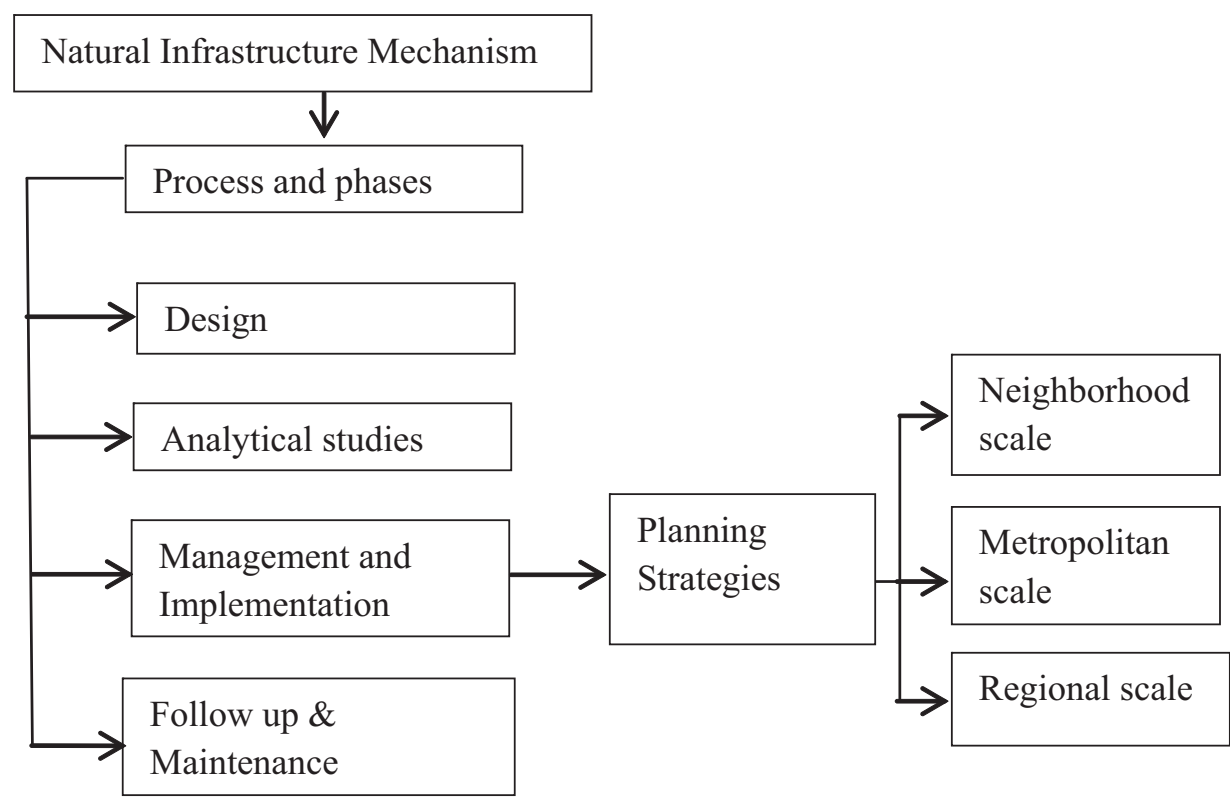

Figure 1: Natural infrastructure mechanism. 


\section{NATURAL INFRASTRUCTURE FRAMEWORK AND PLANNING STRATEGY}

This paper has classified the framework's components into three major analysis units - ecological, social and functional - each of which has specific tools and polices that show the management of the NI project in different scales: local, regional and national. Milton Keynes \& South Midlands Sub Regional Strategy (MKSM) [5] reported that the main determinant of a GI framework is the location, which displays the hierarchy of international, national, regional and locally designated sites and identifies areas that contribute to the restoration, conservation and creation of new GI plans through appropriate policies. Each unit is divided into three main parts: the first is general identifying, the second is the key action that includes steps and points to reach the third part that is the outcomes from every unit. Together, these outcomes form the final step (major outcome), which is a comparative analysis to use as an input to the next part of the paper (Section 4) (Fig. 2).

City Region Green Infrastructure Strategic Planning ECOTEC [6] confirmed the framework for delivering strategic planning for GI in the city regions, and this framework included major key actions that were summarized from different questions resulting in outcomes from different stages to reach the strategy and action plan. The paper focused on the analysis units that can support the in-depth analysis of core cases, together with the comparative criteria to determine the main concept of creating or developing NI projects in different climatic zones in general and, in particular, in arid zones. These analysis units, ecological, social and functional, can affect the planning process on different scales and levels, from regional scales to neighbourhood levels. The main effect can appear in the last three phases of the planning process: management, implementation and maintenance. The role of these analysis units will increase the in-depth analysis of Egyptian case studies to show the relation between the three units with particular cultural and historic aspects. Moreover, the interaction between the social unit and the implementation phase will take the major focus to show the relationships among people, government and private sectors. Therefore, the structure of the NI mechanism represents these relationships, and the unit's effectiveness within different methods can be used for in-depth analysis. The major tool is Geographic Information System (GIS) mapping and it will include different data that relates to these major analysis units.

The planning strategy in Egypt has been developed by the Urban Ministry throughout the 19th and 20th centuries, and has introduced different important aspects into the planning process such as, social, economic and environmental aspects. These aspects improved the quality of implementation and decision making. However, this development of planning strategy does not have specific layers of NI or elements related to it. Also, the planning strategies tend to be limited to the design of green spaces and parks. Thus, the case studies will show the NI projects available in these days in Egypt, and will emphasize the importance of the NI layer in planning strategy.

\section{CASE STUDIES IN EGYPT}

Cairo looks like a desert city surrounded by agricultural land, with a few green spaces between buildings. Its natural corridor is based on a powerful blue infrastructure, which is the River Nile, with GI features on its banks and islands. The Egyptian Government has adopted a programme of restoring the green spaces and green network in Cairo to meet the needs of the community. The 'Master plan of green spaces in Cairo: future vision 2050' proposes a significant increase in green space per capita, General Organization of Physical Planning (GOPP) [7]. 


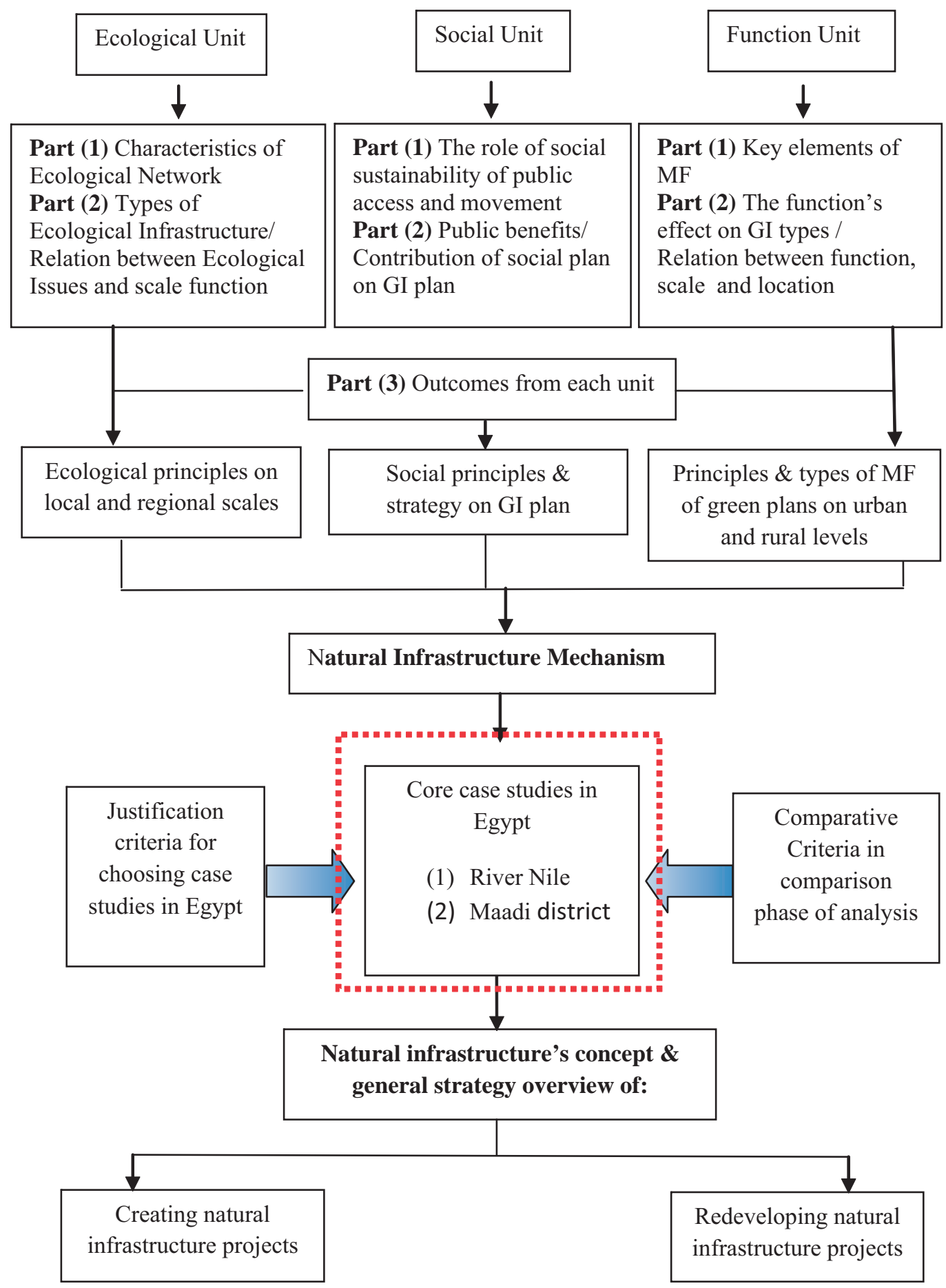

Figure 2: Natural infrastructure framework. 
Irrigation of these new green areas will depend on the use of waste water (especially treated waste water from sewage).

\subsection{Case study 1: Green corridor along the River Nile}

The main theme of this case is inferred from the sociocultural value from the customs and traditions that will be represented in heritage places, together with the powerful NI component, which is the River Nile. Blue and green ways form the connectivity among natural, social and economic elements. This case is represented in two main phases: the first is the description and documentation of the outline of the River Nile and its banks and the second is the criticism between different master plans and analysis of the study area. In the criticism, this paper determines the gaps between different master plans that developed in different eras. This will help in the analytical step that focuses on three main criteria: connectivity, MF and sociocultural sustainability. Then, the paper concludes with the specific elements that contribute to the concept of NI by adding significant values to it. The River Nile in Egypt is an important natural corridor linking Upper and Lower Egypt. In Cairo, it connects different districts that have different characteristics. It is considered as the main blue way that includes natural, visual, environmental, agricultural and economic functions. Importantly, it links historic Cairo and the main ring roads of new modern Cairo and connects the network of open spaces along the river as well.

This characteristic of the River Nile, to connect cultural, historical, touristic and recreational features, can be achieved through developing visual and movement corridors along riverbanks, and improving access to and along the river from the city through the provision of public transport and a network of pedestrian paths, bridges, ferries and bicycle paths.

In this regard, Barada et al. [8] have developed a 'strategic vision' for a River Nile master plan, which proposed a policy that provides a framework for NI, namely: preserving agricultural lands on the north and south banks of the urban areas and the Nile islands; controlling the growth of urban communities through the protection of rural space; and solving the problems of urban sewage and agricultural drainage. The master plan project began in 2001 as a study of a condition survey of the Nile banks and was further developed in 2005 to promote a new planning strategy vision for the Nile within Cairo, as a basic core for functional and recreational features. In this vision, it was recommended to designate all the Nile islands as protected areas [8]. Currently, it has been used for residences and agriculture and some have only water-borne access. In addition, the riverbanks are, or have the potential to be, recreational riverside greenways that include cycleways along the river, pedestrian paths, open green spaces, parks, and green spaces parallel to the Nile, especially in urban and recreational sectors (Fig. 3).

The river is seen as the backbone of a major recreational network linking the tourist and entertainment hubs of the River Nile (banks and islands) with the green and open spaces, as well as the archaeological and cultural sites within Greater Cairo. Furthermore, this vision takes into account the need for economic activities associated with the River Nile. This would be achieved by the extensive landscaping of the communicating network (greenways) with central commercial areas.

4.1.1 The gaps between different Nile master plans produced in different times

There are different master and structural plans mentioning the development of the River Nile and its banks, which recommend activities and land use around it and also advise and suggest 


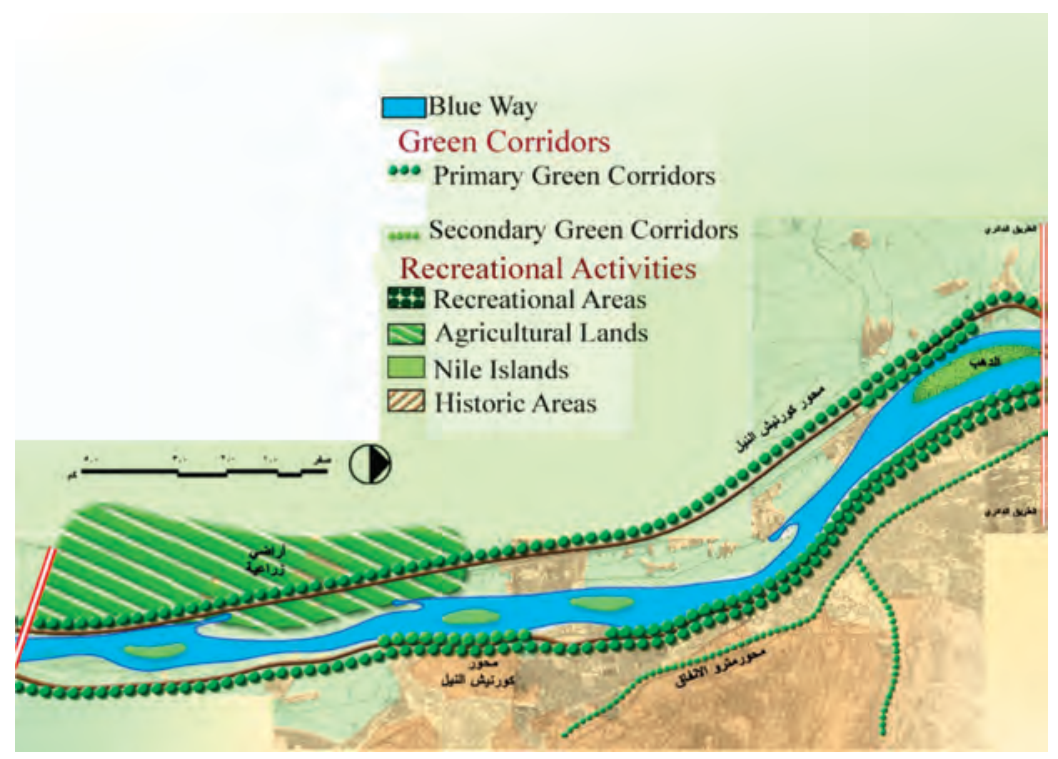

Figure 3: Key natural infrastructure elements in the Cairo master plan (extract) (based on information in Barada et al. [8]).

projects to develop and increase the role of the River Nile. However, some of these recommendations and projects failed to be implemented due to different levels of lacks that created gaps between master plans, implementation and legislation (Fig. 4).

To fill the gaps between these plans, and to ensure that all these projects will be implemented on the ground, the following must be taken into consideration:

- The lack of people awareness and the weakness of education levels to realize the importance of the Nile as an arterial or life way.

- The lack of coordination between different planning and urban organizations such as, the Ministry of Housing, GOPP and Urban Research Consulting Centre.

- The conflict or contradiction between, urban and planning legislation and laws such as, Building Law and Environmental Law.

Spotting these omissions and gaps between different governmental decisions and planning strategies will improve the connection between natural elements in the analysis phase. For example, stopping the implementation of the Nile riverbank development in 2005, due to a lack of connection and contradiction between governmental decisions and planning laws. This highlights the lack of coordination between people needs, government and private organizations. This will affect the sociocultural criteria in the analysis phase and will determine the reasons for unsustainable projects along the river. The ignorance of governmental decisions regarding the types of buildings, their functions and their heights by landlords and landowners is an obvious example of this conflict or contradiction. They used to build vertical shopping malls that collected all entertainment and shopping areas in a scattered and disconnected spot point of attractions. That destroys the connectivity of MF along River Nile. This connectivity might be 


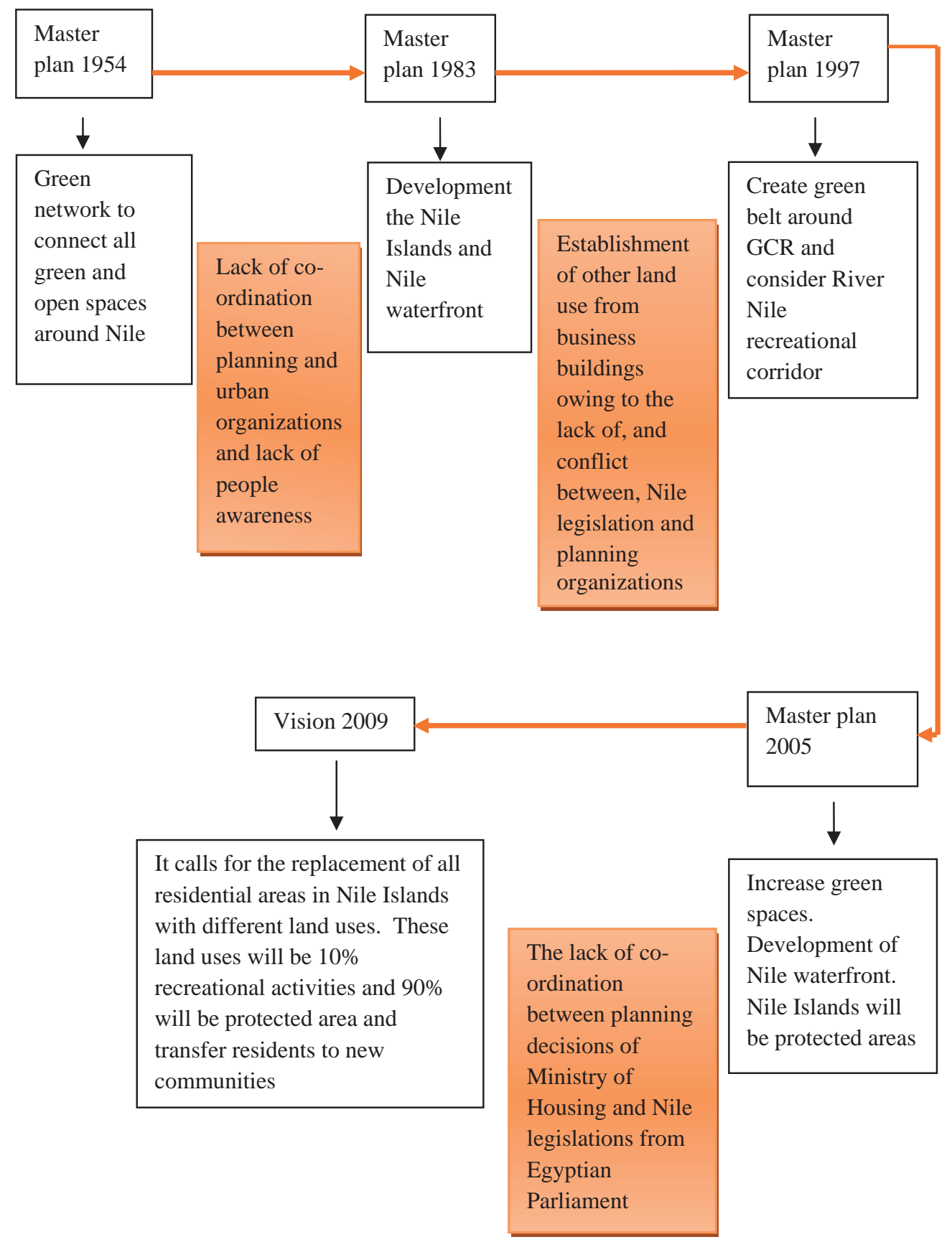

Figure 4: The gaps between master and structural plans of River Nile. 
achieved if they adapted the horizontal development instead of this vertical scattered spot point. This, in turn, affects negatively on a considerable number of recreational functions, which relate to the economic value. This thus affects the connectivity between elements along the River Nile.

4.1.2 Analytical criteria for analysis of the Nile case study

There are three main criteria to analyse this case and these criteria have other analysis elements that help to reach the aim of this case.

\section{Connectivity}

As mentioned before, the River Nile is considered as a natural social and economic link, which connects different islands through the waterway and links different urban districts via major and minor roads. Also, it links different human and recreational activities via the greenway along its banks. All these connected areas represent the natural corridor of habitats, biodiversity, green spaces and hydrology as well. For green spaces, the River Nile connects three islands that have different kinds of open green spaces with similarities and differences (Fig. 5). EL-Zamalek Island has public green spaces along the island bank; there is an opera house and its sitting area and private, open green spaces inside the AL-Gesera Club. Syalt EL-Roda Island has lots of recreational activities based on linear green parks along the River Nile and the green corridor that intersects with the heritage axes. This green corridor has different kinds of vegetation and wildlife. This part will be explained in detail in the MF analysis phase. EL-Dahab Island and its green lands comprise cultivated lands. In the front of these islands along the riverbanks, a considerable number of recreational attractions enhance the connectivity function and improve its natural value, sociocultural customs and historic places. Such recreational attractions are green spaces, horticultural lands, social and sport clubs and green parks. For hydrology, the River Nile is the main blue way for different functions and uses; it is the main source of drinking water, irrigation for agriculture land and recreational places, and is a

Table 1: The analytical criteria of the Nile case study.

\begin{tabular}{ll}
\hline Criterion & Sub-evaluation criteria \\
\hline Connectivity & Green spaces \\
& Hydrology \\
& Circulation \\
Multi-functionality & Wildlife \\
(no. of functions) & Passive leisure \\
& Active recreation \\
& Food production \\
& Timber \\
& Groundwater recharge \\
& Microclimate \\
& Environmental education \\
& Public spaces \\
Sociocultural & Cultural asset \\
sustainability & Community maintenance \\
\end{tabular}




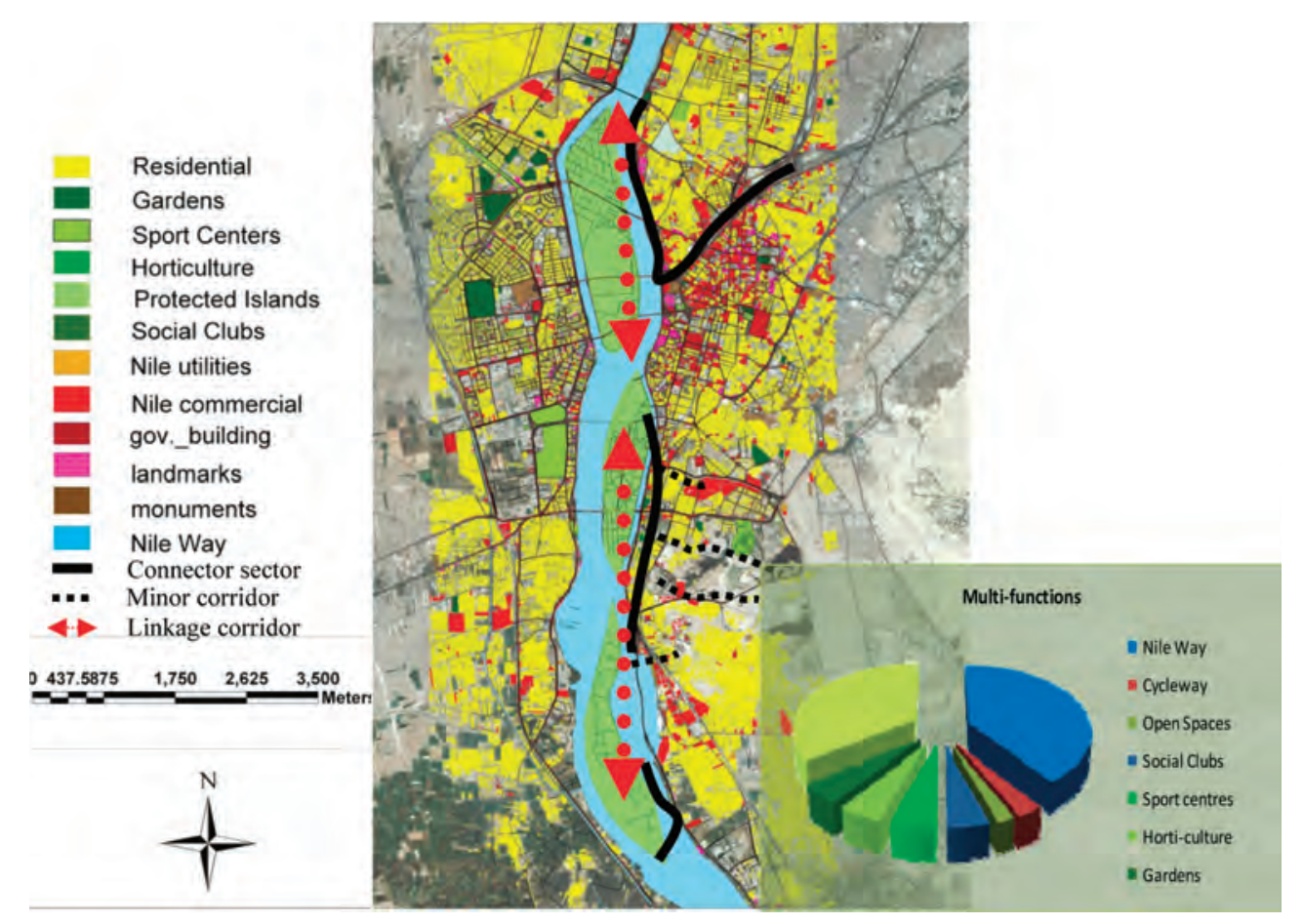

Figure 5: The connectivity along River Nile 'Green spaces, hydrology, circulation'. GIS map by author.

transportation means for people, communities and tourist purposes. Thus, it improves and helps the economic base of Cairo and develops social, environmental and natural values. Moreover, there are different conduits, lakes and streams from the River Nile to serve different agricultural lands and urban districts that do not have direct access to the main body of the River Nile.

However, there is no existing hydrology features except the River Nile. Before the end of the 19th century, there were two conduits: one is the major stream that branched from the Nile at EL-Roda Bank to supply Medieval Cairo with water. This stream was filled in at the end of the 19th century to be used as a major road connecting historic Cairo with modern Cairo. The second was started from EL-Dahab Bank to supply the Maadi district with water since it was an agricultural land. But this conduit was filled in and transformed into a street because of the encroaching urban development and building growth in Maadi district.

For the circulation, there are two kinds of transport network along and around the Nile: vehicles and pedestrian. The study area is located on the major Nile way (Corniche) and there are different major and minor road intersections with the Nile way, such as Salah Salem highway and 15 May Road. The Corniche is well maintained, which provides opportunities for one continuous route along the riverbank and Greater Cairo. Also, there are two bridges crossing Syalt EL-Roda Island and three major bridges crossing EL-Zamalek Island. Also, in some parts of the riverbanks, there are cycleways beside the pedestrian path, in particular, and in recreational places, such as the cycleway along the River Nile in Syalt EL-Roda Bank. Moreover, the shaded pedestrian paths are spread all over the recreational places. Therefore, these types of circulations are expected to improve the connectivity in terms of its MF. 
From these sub-evaluation criteria of connectivity, green spaces, hydrology and circulation, the paper proposes a natural way, which is the River Nile and its banks. This natural way links the functions that are located in the greenway along the River Nile. Consequently, this would improve the connectivity in terms of the social and economic values via enhancement of recreational value. These values preserve the microclimate by using special native plants and groundwater recharge. Also, this natural way connects the blue way, which is the Nile water, with its islands, thus improving the quality of food production and reducing the expense of irrigation system for agriculture lands. Moreover, the connection between these islands and their banks increases the relation between historic places and natural resources and helps to develop environmental education and people awareness. The linkages along the River Nile and its surrounding urban areas shape the natural, functional grid that is based on the long natural course of the River Nile and the intersected axes at right angles with the Nile (Fig. 6).

\section{Multi-functionality}

The riverbanks are, or have the potential to be, recreational riverside greenways that include cycleways along different parts of the river, pedestrian paths, social clubs, open green spaces, parks, and green spaces parallel to the Niles, especially in urban and recreational sectors. As mentioned previously, there are some recent studies recommending that the islands of the Nile be considered as protected areas [8]. Currently, these islands are residential areas suffering from a lack of clean water, although they are surrounded by the river on each side. The main use, beside residential, is for agriculture. In addition, this river is seen as the main spine that connects the recreational network of Greater Cairo, as it links tourist activities, entertainment hubs, green open spaces along the riverbanks and, importantly, historic and cultural sites. Recent studies investigate the needs of economic activities that have been accommodated along the riverside, such as, tourist marinas, transportation along the River Nile and commercial areas. The investigation and study highlighted the need for an extensive and effective connecting network composed of several levels of greenways and green

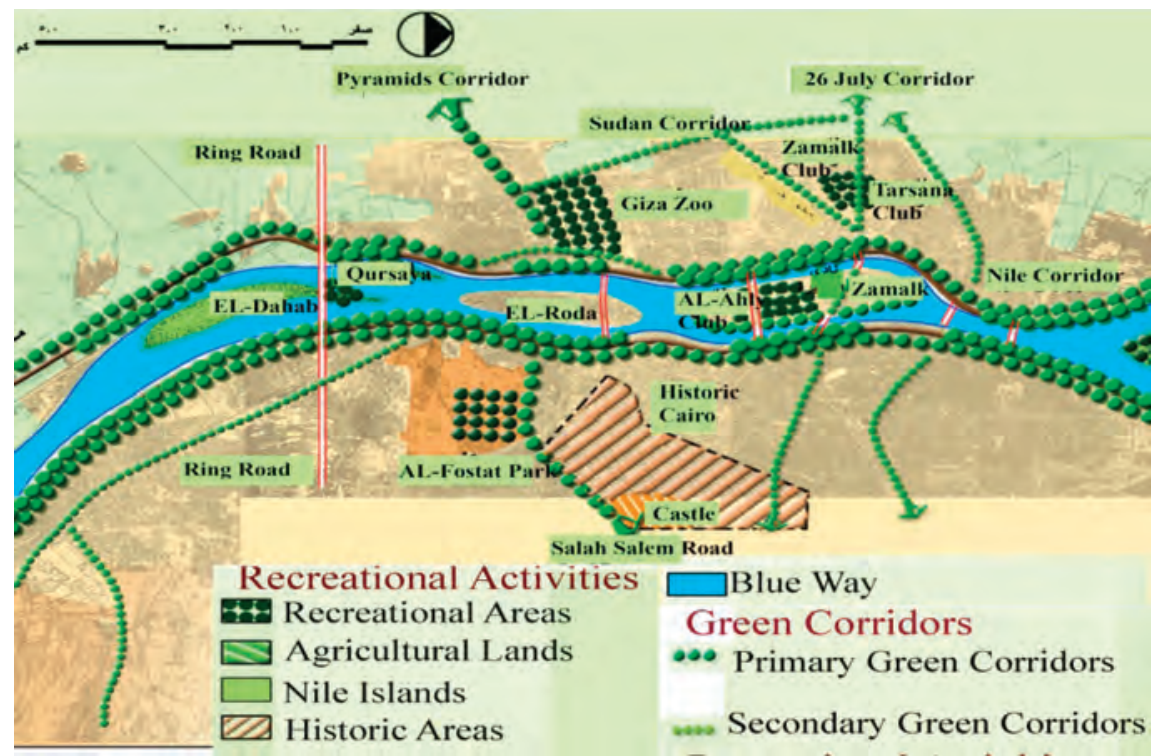

Figure 6: The proposed natural grid connects River Nile with intersected axes. Map by author. 
corridors, not only to connect the activities that are accommodated along the River, but also to connect these activities with central commercial and cultural areas in the heart of the city [9]. In addition to the River Nile as the major link for different activities and as one of the important circulation corridors, there are other roads parallel to, and intersecting with, the river that act as another layer of links and circulation, and also accommodate various commercial utilities and public services. All but few depend on the River Nile as the main route that all functions must relate to the River Nile as a waterway can be used for different functions, such as boat marinas, waters ports and Nile cruises. The analysis of all these functions is based on the number of these functions in each segment of the Nile. This paper divides the study area into three main zones and two minor zones. In some areas from each zone, there is an overlap between functions in the other zone, for example, the first and second zones, where there is an overlap between the recreational activities of each zone. This division is related to the functions of each zone and the natural division that refers to the Nile Islands (Fig. 7).

The main function of AL-Zamalek Island and its eastern bank zone is the recreational function for active and passive leisure. The island is known by the Gezira Sporting Club, which is located there and was established by the British in 1883. It is the most extensive green space designed and established in modern Cairo, besides other prestigious landmarks of the modern city, such as Cairo opera house and the recent Cairo Tower. Accordingly, this paper suggests a recreational centre that links River's landmarks, green spaces, social clubs, cycle way, commercial malls and other recreational activities within residential areas. Also, this centre connects the major and minor roads within green routes that are covered by different types of trees, streetscape connectors and vegetation (Fig. 8). For example, the trees and plants affect the micro-climate, because they make the climate

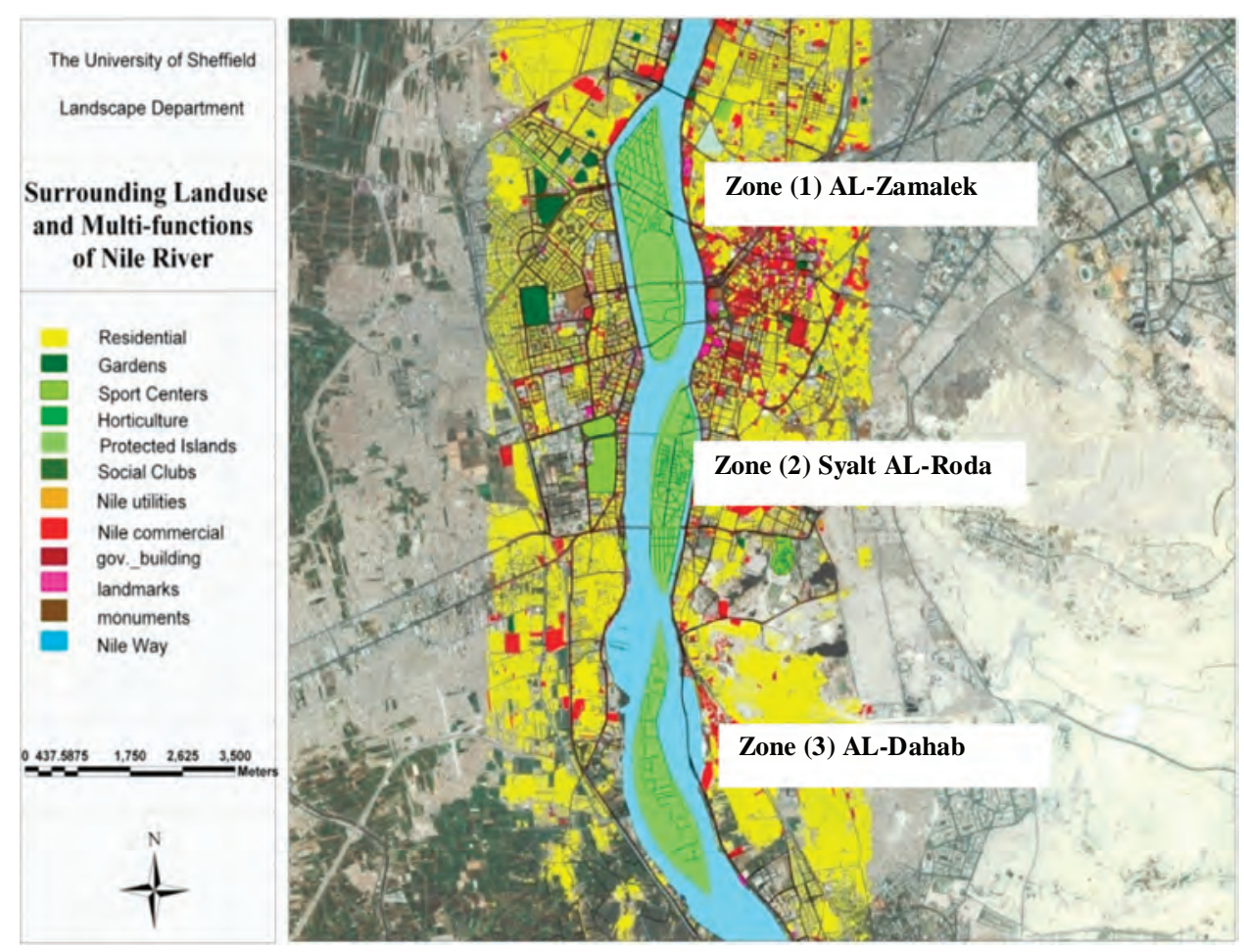

Figure 7: The MF of each zone of River Nile. GIS map by author. 


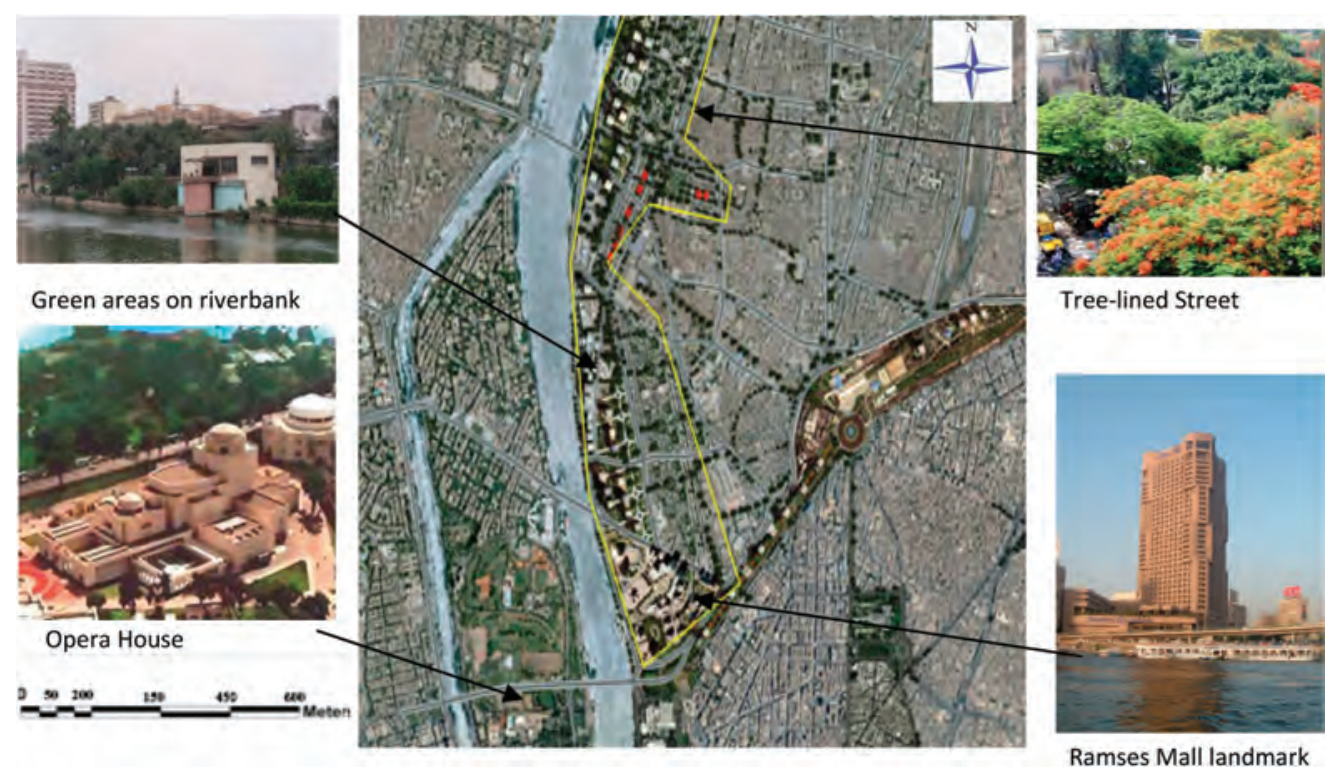

Figure 8: The proposed recreational centre in AL-Zamalek Island bank. GIS map by author.

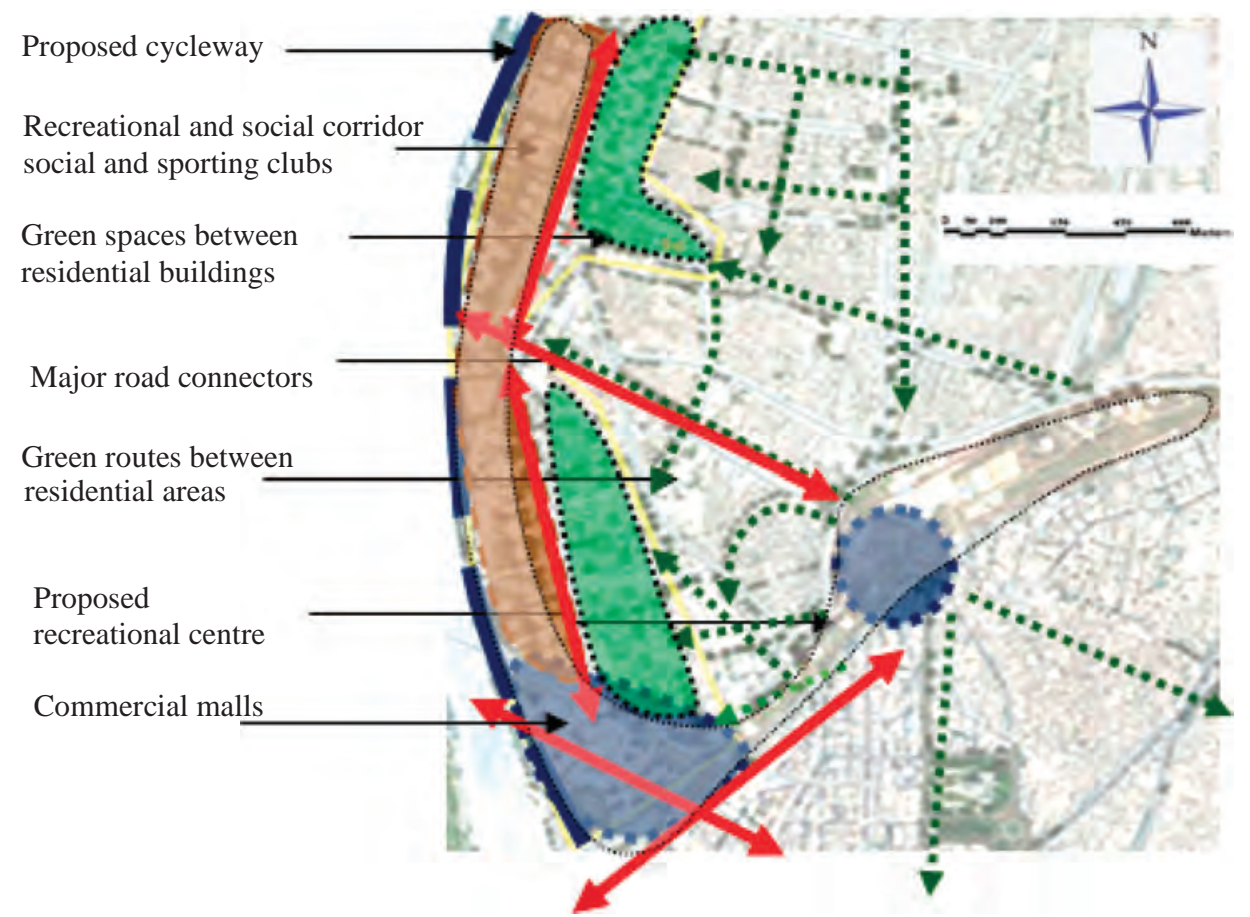

Figure 9: The functional connectors of proposed recreational centre in AL-Zamalek Island bank. Map by author. 
cool, particularly in the summer. These plants preserve water, thus there are water plants including Lotus, more than 100 kinds of grasses, palms and reeds. Moreover, the planted streets, streetscape, connect the minor roads and river's landmarks with the Nile Way. The connectivity between recreational centre elements is improved by major roads connectors, which link the recreational corridor along the River Nile and the commercial malls, as well as the green open spaces within residential areas. These will increase the connectivity between recreational elements, by improving the quality of vegetation, increasing the active recreation and developing the microclimate by reducing the air temperature via these green routes with lush vegetation (Fig. 9).

The second zone is the Syalt EL-Roda Island and its eastern bank. This zone or segment is considered as a heritage, historic and cultural corridor. This article has recommended a historic, cultural corridor that connects four main axes: the Religions Compound axis, the Great Mosque of Amr Ibn Al-Aas axis, the Menestrel Palace garden and the Ministry Palace garden and Nilo Meter axis. These axes connect the historical traditional city with the River Nile corridor via a powerful visual axis to the waterfront of Nile. Therefore, the proposed cultural corridor would link these four axes from the south to the north along the bank of the River Nile in front of Syalt EL-Roda. Moreover, this linking axis can be designed as a River garden that accommodates all the leisure and entertainment activities that match these four axes.

This paper recommends that these historic axes will be connected together through the main corridor, the River Nile bank of Syalt EL-Roda. Also, they will be linked by the major and minor roads that intersect with the Nile axis, such as AL-Manial Street, and some bridges such as AL-Malek AL-Saleh Bridge. This connection between the historic elements improves cultural values for people. For example, the Religions Compound axis has the Suspended Church and

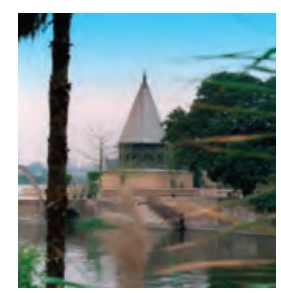

Menestrel Palace garden Axis 4

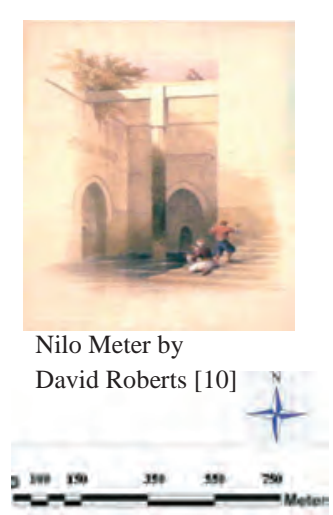

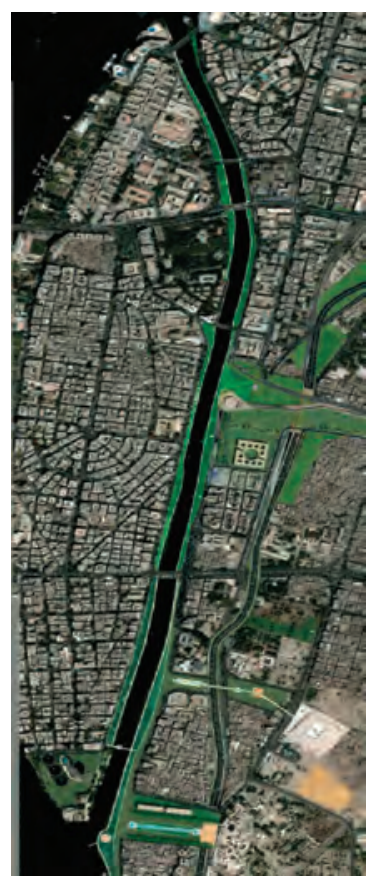

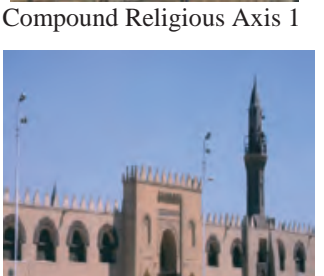

Amr ibn Al-Aas Mosque Axis 2

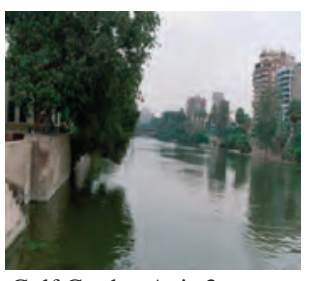

Gulf Garden Axis 3

Figure 10: The proposed green corridor connects Syalt EL-Roda Island and its intersected historic and cultural axes. GIS map by author. 


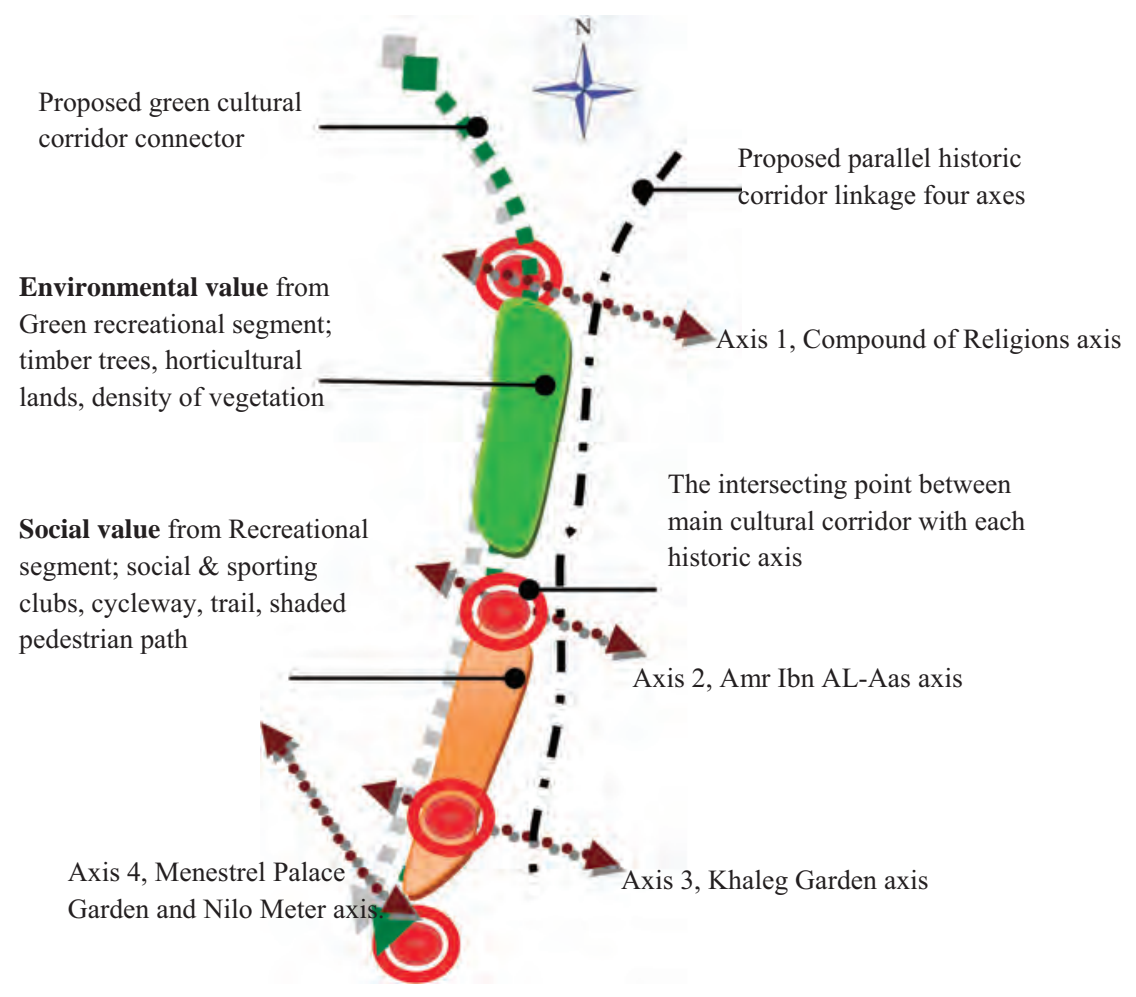

Figure 11: The functions of the proposed cultural corridor within two main segments through different values. Map by author.

people consider this Church to be a holy place, because Jesus stayed in this church for a few days when he was in Egypt. Additionally, the Amr Ibn Al-Aas mosque axis has the great mosque, which was built in the 7th century and people consider this mosque to be a historic place for the early Islamic period in Egypt. Moreover, the Syalt EL-Roda bank is well known by the recreational activities, such as watersports clubs, social clubs, green spaces, trails, cycleway and shaded pedestrian paths that provide recreational value to this area. Importantly, it has different kinds of vegetation and horticultural lands that help to cool the climate and develop a visual image of green linkage. Increasingly, some trees are used in food production, in particular, fruit trees, such as date palm, fig trees and banana trees, which improve the environmental value (Figs. 10 and 11). Also, the timber trees, that improve the benefits from natural materials, are found in this zone, such as Cyprus papyrus and bamboo.

The third zone is the EL-Dahab Island and its eastern bank. The main function of EL-Dahab Island is the agriculture and it supports food productions. That is because it has different crops, such as grains and vegetables. The population of this island is 20,000 people with poor levels of education and the Government decided to make this land a protected island. Therefore, the authority offered new places for the local inhabitants to move to. However, some of island's inhabitants ignore and refuse this governmental decision and are still resident on the Island and the Habitat International Coalition (HIC) supports them to stay there. Additionally, 'The 
lack of public services and facilities on the island is due to two contradicting issues that the island's inhabitants have faced since 2001. The first is the government's plan was to sell the land to developers for touristic purposes and the second is the government's declaration of the island as a natural reserve' [11].

Moreover, the environmental education programmes have been involved in the development of this island. Harris [12] has started programmes to bring education and medication to the residents, and to train inhabitants to preserve the natural places on the island and know their own rights with the authorities. However, the environmental aspect is one of the most important aspects of this island. The agricultural land is based on Nile water for irrigation. The waste from agricultural land and animals is thrown directly into the Nile. Also, the waste drainage system pollutes the Nile water considerably. The other passive impact on the environment is a result of building work on the islands. The agricultural soil, which is rich in minerals important for wildlife, cultivation and agriculture, has been removed owing to the encroachment of urban areas. This island is a stopover for migrating birds, such as, white storks and little gulls, other inhabitants such as the indigenous frog, Bufo kassasii, and different kinds of Nile fish, such as Anguilla spp., Mugil cephalus and Solea vulgaris.

\section{Socio-cultural sustainability}

This natural corridor connects different cultural assets through four main cultural axes that include heritage and historic sites. Some traditions and customs might happen in public spaces along the River Nile. For example, the Nile festival, the celebration of the Nile flood, is celebrated every
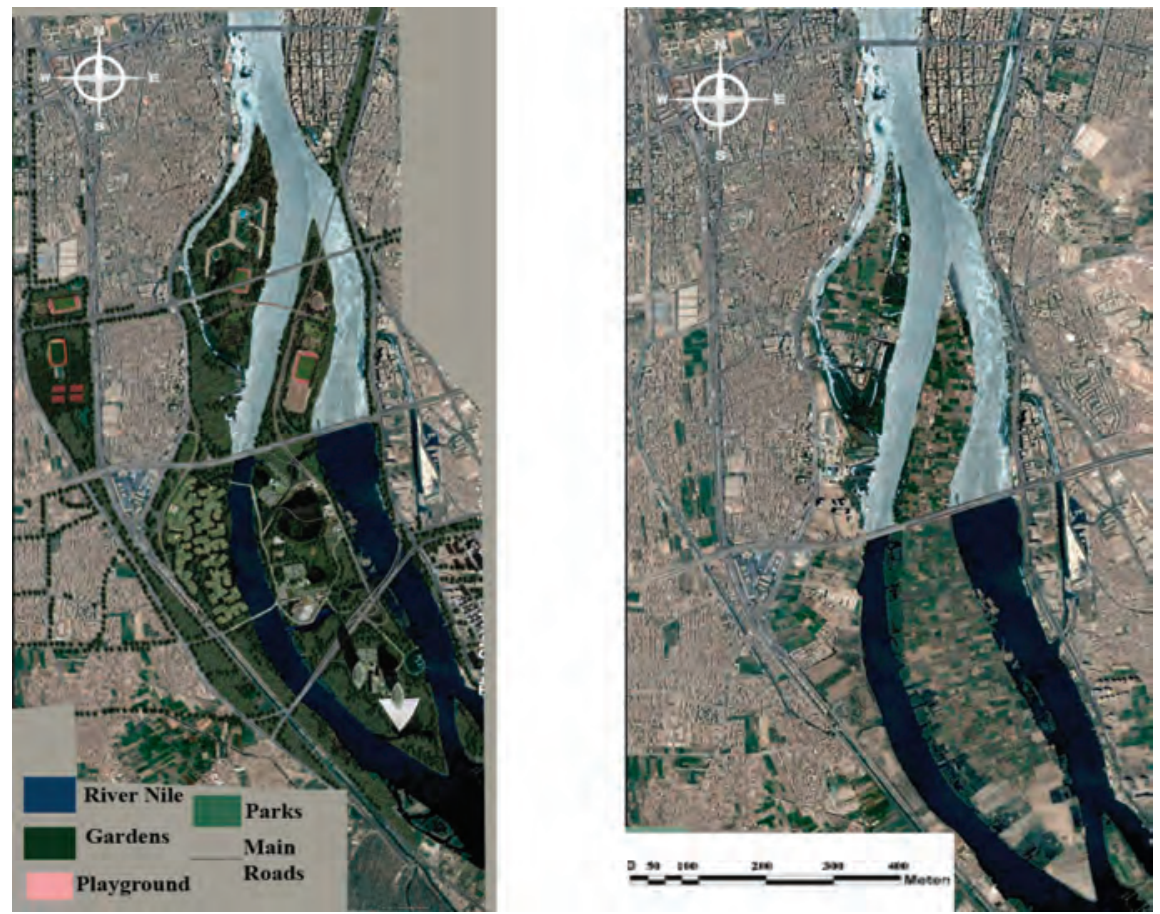

Figure 12: Right: The existing cultivated lands in EL-Dahab Island. Left: The suggested proposal for the island after inhabitant evacuation. GIS map by author. 
year at Easter time, by special parties marking the specific traditional ways and customs of the Ancient Egyptians from sunrise to sunset. This event is called Cairo's Wafaa Al-Nil Festival, meaning Fidelity of the Nile, and reminds people of the importance of the Nile. Traditionally, before Islamic times, at this festival, the authority used to throw a beautiful girl into the water Nile to be as sacrificed to guarantee a good harvest. But nowadays, the celebrations focus only on the arts, poetry, concerts and scientific discussions. This celebration takes place in public spaces on Syalt EL-Roda bank and is organized by the Ministry of Culture. However, there is no official entity that serves as a connection between different organizations, such as the Ministry of Housing and the Ministry of Culture. Accordingly, Barada et al. [8] suggested that the Egyptian Environmental Affairs Agency of the Council of Ministers could achieve a kind of integration and coordination and have ultimate responsibility. It should be borne in mind that creating a new administrative entity can increase overlap and conflict, if its tasks are not tightly and accurately formulated.

\subsection{Case study 2: Green network of Maadi and Wadi Degla protected area}

The main theme of this case is that the green network and ecological corridor connect the natural protected area with the urban district. This case shows two different urban features: the first is the Maadi urban district, which has a green network and is connected with the River Nile at its entrances. The second is Wadi Degla, the protected area that has different ecological and natural elements.

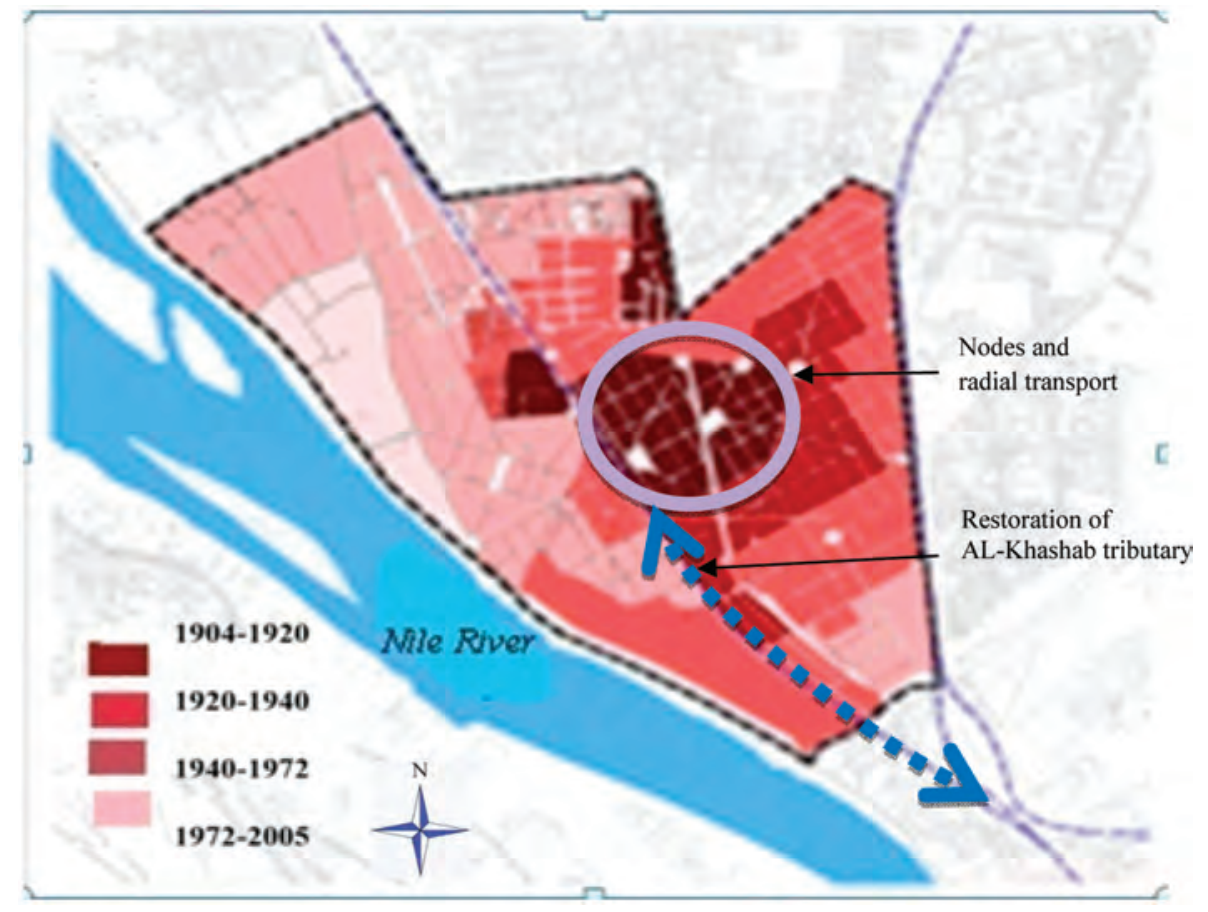

Figure 13: The historical development of Maadi district. Map by author based on information from Raafat et al. [14]. 
Therefore, this paper represents these areas within two main phases that are the historic descriptions and the analysis phase, and explores the relation between them.

\subsubsection{The historical development of Maadi}

'The land of Maadi district was agricultural when the first railway for mines was established in 1873. The design of the town was based on nodes and a radial transport axis, with parks and public lands and in 1909, the first metro line of Maadi was established' [13]. In 1921, the Golf Club was built and changed its name to Maadi Sporting Club and the common use of land in this period was residential use. During the early 20th century, it was mainly residential but there has been subsequent development of commercial units, small factories and military training areas (Fig. 13).

Therefore, this case aims to restore the ecological, historical and environmental balance, such as the blue way of Al-Khashab tributary, to maintain and preserve native plants and improve the natural soil.

\subsubsection{Wadi Degla protected area}

The area of Wadi Degla has been considered as a listed and natural protected area since 1999 by Ministerial Decree No. 47 of 1999. The Wadi Degla protected area surrounds the Maadi district to the east and it is considered to be a provincial park, which is divided into two zones: core area and managed resource zone [15]. The first zone, the core area, is the Degla Valley that includes different environmental and natural elements, such as caves, geological forms, biodiversity, waterfalls and habitats. The second zone is the managed resource that is considered as a buffer zone surrounding the first zone to protect it. Also, it includes different cultural and recreational activities

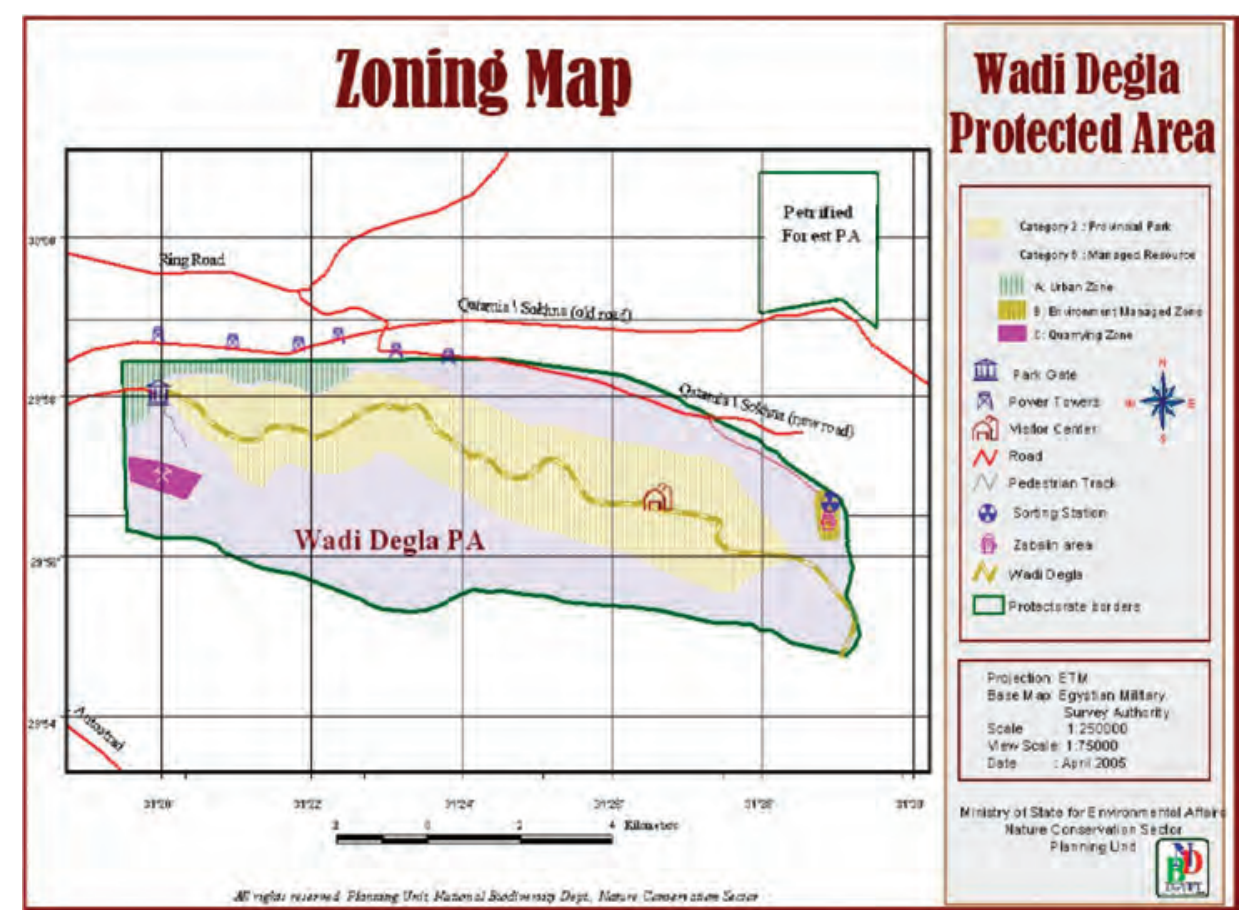

Figure 14: The Wadi Degla protected area zones [15]. 
that follow the regulations and instructions of the protected area from the Ministry of Environmental Affairs. These activities are distributed in three zones: quarrying zone, multiple use zone and urban area (Fig. 14).

\subsubsection{The analysis phase}

In this stage of analysis, the paper focuses on the major three analytical criteria as mentioned in the Nile case. However, this case has more environmental and natural richness than the previous one. This makes the components of this analysis more oriented to the NI concept as it is known in European countries. The article analyses the connectivity in this case on two levels, within Maadi district, and between the district and the Wadi Degla protected area. Consequently, the paper links between the functions in separate areas and the sustainable development of those levels.

\section{Connectivity}

Maadi district is a good example of linking areas and connecting elements. The connectivity here is related to its potential and its important places. 'There are four specific potentials of Maadi district that make this district valuable visually environmentally and historically. First, the western frontage of Maadi district is exposed to the Nile, which gives the location its unique urban character and recreational value. Second, the preservation of valuable and historic buildings gives this district special visual character such as classic, neo-classic and Victorian houses. Third, the recreational and environmental places are spread all over the district composing a green network with historic blue way (Al-Khashab tributary); this conduit is considered as a natural recreational way crossing this district. Third, the location of Maadi district near the Wadi Degla gave this district special character. Fourth, the radial planning concept of this district makes the creation of green network easier, because the simplicity of road design produces a more harmonious urban spatial form, in contrast to the morphology of Cairo' [13]. Moreover, the Maadi district's entrances from the edge of the River Nile provide a major opportunity for connecting recreation and tourist elements. Also, Wadi Degla edges the district from the east and gives this district a unique natural connection, notably for biodiversity. However, the northern land use of this study area is for slum areas that have a different urban form and social behaviour. Additionally, the green nodes and green spaces are spread throughout the district. The green nodes are designed according to the radial axes. The open green spaces are common in social clubs and the Maadi sport centre. All the houses were built as villas or palaces with private garden and horticulture lands that magnify the green aspect of the district, creating its uniqueness.

Additionally, there are many native plants that have historic value in the Maadi district since 1873 when the district was established in the 19th century. These historic plants have been surveyed and well documented as an advance step to being evaluated according to their conditions and characteristics. The GOPP (2005) [16] suggested three new types of vegetation for the renewal and revival of the existing plants, which are grass, shrubs and palm trees. For the first type, grass, it suggested to be used in an open green area, using special kinds of grass, Pennisetum purpureum and Pennisetum setaceum, which do not need a lot of water and can withstand intensive use. The second type is shrubs of different colours such as red, yellow and orange, which give the district its beautiful image. These shrubs preserve water and their maintenance is very easy and cheap as well. Supporting this, the district is well known by special types of shrubs, such as Rosmarinus officinalis, Rosa hybrid and Abutilon pannosum. The last type is palm trees such as Phoenix dactylifera, which is used to emphasize the entrance of district. For the hydrology, the main blue corridor, the River Nile, skirts Maadi 


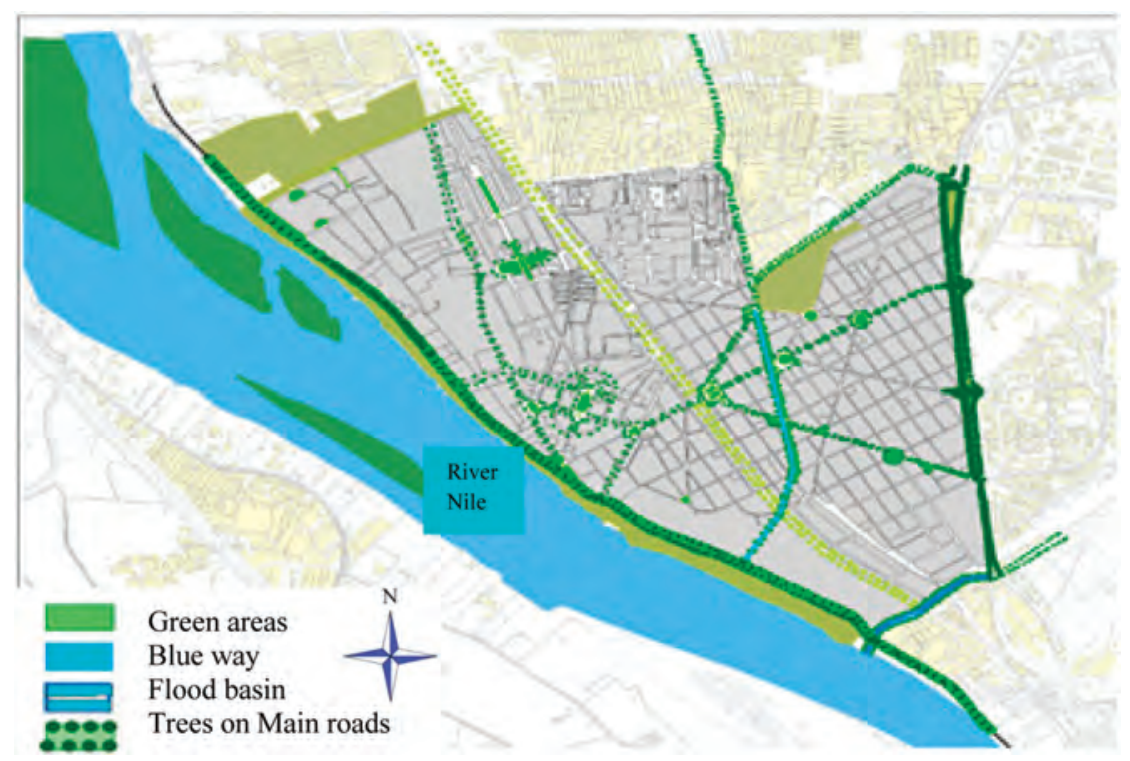

Figure 15: The proposed development of natural networks (green-blue) in Maadi district and River Nile banks. Map by author.

district to the west. It has been proposed to restore the historic canal of the Al-Khashab tributary as a scenic blue way [14], but recently it had been converted to a pedestrian path and greenway and will be supplied with water from the River Nile and furnished with native stones and rocks. Then, the ecological balance is achieved (Fig. 15).

\section{Multi-functionality}

This case is rich in natural multi-functions, in particular the protected area. It is well known for its environmental, ecological and natural functions, which integrate with the functions of Maadi district, that is, the green network function. The green network function in Maadi is based on the district's radial grid. The nodes of this radial grid have a historic value as well as rare plants with a higher density of trees. Road edges and green pedestrian paths connect the nodes and green open spaces via green links. Maadi district is also a key water catchment and includes canals and conduits along drainage buffers.

Many important plants have colonized the Maadi district since its establishment in 1873, broadly comprising grasses, shrubs and palm trees. Raafat et al. [14] proposed a NI based on grassy areas comprising: species, which require little water and tolerate intensive use, a colourful choice of flowering shrubs with low water and maintenance demands, and palm trees emphasizing the shape of nodes and the urban entrance.

To improve the green network of Maadi district, this paper recommends two main suggestions to balance natural and ecological functions. First, revive the natural elements in the green network and return them to how they were in different historic periods, such as the blue way of the Al-Khashab conduit. Therefore, the present account proposes some recreational activities on this conduit based on information from Raafat et al. [14]. The activities are shaded pedestrian path, open green spaces and artificial water fall within natural rocks at the beginning of this blue way. The restoration of the 
Al-Khashab conduit will enhance the functional and visual images of Maadi district. Also, it will magnify the environmental balance by reviving the historic character and natural spirit of this area. Additionally, this restoration of the Al-Khashab blue way will support the agricultural lands through the direct irrigation system and improve the economic value of this conduit. Secondly, the documentation of all historic plants that help planners and landscape researchers to review these natural elements will allow planners to make a quick check and treat these plants in the maintenance phase. For wildlife, Wadi Degla has special distinct animals, such as the Dorcas gazelle, 75 types of native plants and 20 kinds of reptiles. Also, the Wadi Degla protected area is part of a limestone plateau within the Degla Valley. The width of this valley is about $50-100 \mathrm{~m}$ and it is surrounded by hills of 150-250 $\mathrm{m}$ in height. The biological diversity provides the Degla Valley with an important ecological value as the only example of an ecosystem in Egypt's Northern desert. Also, the ecological and geological configurations support and save the biological diversity from extinction. For example, the caves are suitable places to shelter some animals and an important environment for pats and some birds such as rock doves and owls. Another importance of these caves might appear in the study of climatic changes through previous ages.

\section{Sociocultural sustainability}

One of the main aims of this paper is to develop a concept of the Maadi district, within the holistic approach of GI in arid areas, as a multi-culturally distinctive network. This is presented in two phases: an urban management phase and an implementation phase. The urban management phase comprises three tiers of organization, namely: local government (council), a non-governmental organization (NGO) and the private sector (stakeholders, Maadi Company). The NGO has a particular role to manage urban projects and urban decisions, and there is a sharing of responsibility between the council and the Maadi Company for building processes and guidelines. The implementation

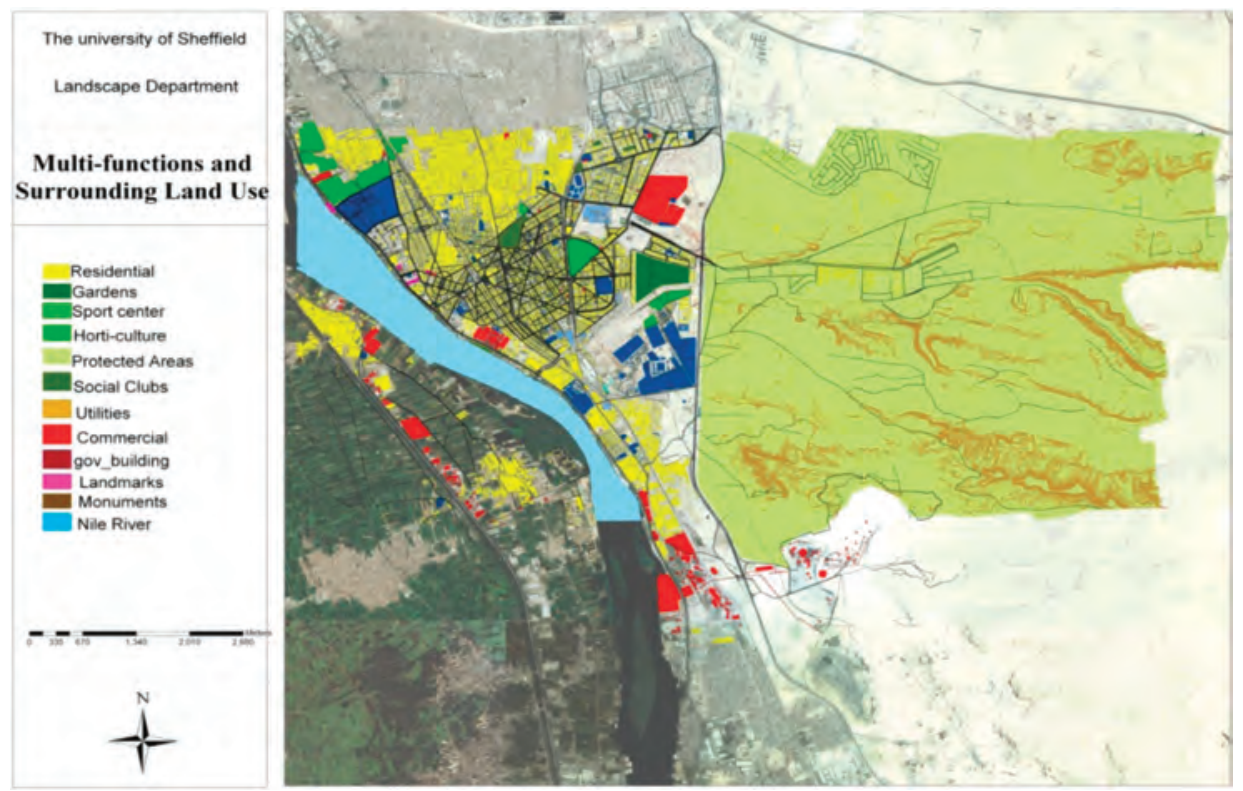

Figure 16: The surrounding land use and MF of Maadi. GIS map by author. 
phase entails cooperation between the Government and the private sector in order to sustain momentum. Raafat et al. [14] reported that there are three levels of implementation: long-, medium- and short-term projects of environmental landscape [9].

The long-term projects are considered as a strategic vision for the future over the next 50 years, such as changing the flyovers that divide the Maadi district into two parts by subways, and removing the army camps and reusing the area by creating a cultural theme park. The medium-term projects will be over the next 25 years and some of these projects can be implemented in the present period and others in the future. These projects are: the development of roads and nodes, the development of Maadi edges and surrounding urban areas, and the development of public transportation network connections with underground stations. That is, to create an alternative road instead of the current road from Maadi (entrance 2). The short-term projects would be for 5 years and these projects cover people and environmental needs, such as developing the Al-Khashab conduit into a recreational path and redeveloping the Nile elevations and Maadi entrances.

However, the Wadi Degla protected area does not include any customs or traditional activities. It serves some social, cultural and educational activities for the local community of Maadi district and for visitors from different places. It has different values of resources that contribute to great environmental awareness for the Degla area and for other protected areas, via its central management. The central management in Wadi Degla manages different activities in this protected area, which is considered as an example of sustainable development of protected areas in Egypt. These activities are located in three sectors: quarrying sector, multi-use sector and urban area sector. In each sector, there are different activities that dominate. For example, the multi-use sector is located upstream and has different cultural and recreational activities, general awareness activities, and research and sustainable development activities. Moreover, Wadi Degla has a significant network of development activities such as the Wadi Degla social club, the Petroleum Company and the Maadi residential area. These activities around the protected area increase the connections and cooperation among residents, visitors and the protected environmental organizations in the district. There is some infrastructure in this protected area, which has been used for educational purposes, such as the visitor centre. This centre includes lecture rooms, laboratory, library, museum, café, offices and toilets. This will offer a good place for visitors to enhance environmental education; in particular, most of visitors are groups of schools, universities and educational institution.

\section{CONCLUSION}

To sum up, in the River Nile case, the holistic approach of greenway, open spaces, pedestrian paths, cycleways and other recreational functions will, together, improve the access and circulation between the centre of urban districts and the recreational access along the River Nile. Increasingly, it will develop the natural, economic, tourist and cultural values for communities around the Nile. The natural value is very clear from the blue way, lush vegetation and wildlife. The economic value can be seen via the recreational and commercial functions along riverbanks and also via the Nile trips on the river bus and Nile cruises. The cultural value is the most important one in this case besides the natural value and focuses on the heritage and traditional historic communities. Consequently, the connection between all these values throughout the River Nile and via different green corridors will improve the concept of NI in Cairo. This concept will add these 'natural, economic, social, cultural' values to the green concept of NI, to create one of its major components, which is the sociocultural corridor. Moreover, this natural way of the River Nile should be robust within the hierarchical network of multi-functional green spaces, with a different access to recreational activities. Consequently, this will improve the quality of life and will deal with the River Nile as a main body of social life in Cairo within a landscape sustainable of management and planning strategy. 
Table 2: Differences between the two cases.

\begin{tabular}{|c|c|c|}
\hline & $\begin{array}{l}\text { Strategies case } 1 \text { (based on the } \\
\text { linear natural grid that connects } \\
\text { River Nile with heritage-intersected } \\
\text { axes) }\end{array}$ & $\begin{array}{l}\text { Strategies case } 2 \text { (based on } \\
\text { the network connection of } \\
\text { green network and Wadi Degla } \\
\text { protected area via an ecological } \\
\text { corridor) }\end{array}$ \\
\hline $\begin{array}{l}\text { 1. Ecological network/ } \\
\text { connectivity }\end{array}$ & $\begin{array}{l}\text { The connectivity along the River } \\
\text { Nile increases the relation between } \\
\text { historic places, natural islands and } \\
\text { other environmental resources. }\end{array}$ & $\begin{array}{l}\text { The ecological balance will } \\
\text { be achieved via restoring } \\
\text { Al-Khashab conduit and its } \\
\text { connection with Maadi district. }\end{array}$ \\
\hline $\begin{array}{l}\text { 2. Sociocultural } \\
\text { sustainability }\end{array}$ & $\begin{array}{l}\text { The linkages along the River Nile } \\
\text { and its surrounding urban areas } \\
\text { develop the environmental } \\
\text { education and people awareness. } \\
\text { However, there is no official entity } \\
\text { that serves the connection between } \\
\text { people and planning organizations. }\end{array}$ & $\begin{array}{l}\text { The environmental awareness } \\
\text { improves social values and } \\
\text { also increases the cooperation } \\
\text { between people and NGOs and } \\
\text { governmental organizations } \\
\text { (GOs). } \\
\text { But the sustainability will be } \\
\text { maintained if the role of NGOs } \\
\text { are still working considerably } \\
\text { and effectively as the NGOs } \\
\text { have an influential role in the } \\
\text { planning process, particularly the } \\
\text { implementation phase. }\end{array}$ \\
\hline 3. Multi-functionality & $\begin{array}{l}\text { The functions of this case } \\
\text { composed of different access of } \\
\text { recreational activities and heritage } \\
\text { axes that will improve the social } \\
\text { and cultural values and, in turn, } \\
\text { improves the quality of life. } \\
\text { But if the sustainable management } \\
\text { has not been taken into account } \\
\text { in the planning strategy, the gap } \\
\text { between different planning } \\
\text { organizations will increase, } \\
\text { particularly in implementation } \\
\text { phase. }\end{array}$ & $\begin{array}{l}\text { The ecological and geological } \\
\text { configurations are connected } \\
\text { with the recreational activities } \\
\text { that have been existed within } \\
\text { green network, thus the balance } \\
\text { between natural and ecological } \\
\text { functions can be achieved. } \\
\text { However, if this balance is not } \\
\text { achieved, the connection between } \\
\text { the green network in the district } \\
\text { and Wadi Degla protected } \\
\text { area will be missed out since } \\
\text { this connection is based on the } \\
\text { environmental nature of place. }\end{array}$ \\
\hline
\end{tabular}

As a result, the Wadi Degla protected area provides environmental, educational and ecological value to the Degla area and increases these values through its connection with Maadi district that has cultural, natural and economic values. This connection exists through the corridor that links the two areas together. This link could be improved by increasing the activities and housing new ones on this corridor, through social recreation, healthy and educational activities. The ecological and environmental values provide significant potential for this connection from their biological 
biodiversity, which improves the educational and social values through different awareness programmes from environmental organizations, in the visitor centre in the Wadi Degla protected area. These programmes are for visitors, especially for groups from schools and universities, and there are specific programmes to educate the workers in this area. This environmental awareness improves social values and also increases the cooperation between people and responsible organizations.

Additionally, it improves the cooperation and connection between the Government and the private organizations to meet the needs of people and their communities. For example, the first NGO in Maadi district is called Malth. It was established in 1954 and, after 1964, the name of this organization changed to The Tree Lovers group, and it had a great role in preserving and maintaining the historic landscape in Maadi. This group is an NGO and many of its members are volunteers. They have a good understanding of people's needs and are considered as connecting the circle between people's needs and governmental decisions. Also, there is another example about a private company, which established the Maadi railway and has linked governmental building legislation, people's needs and landlords, as a way of developing and preserving the Maadi urban community.

Finally, from those two cases that are rich in natural and environmental features, this paper recommends specific planning aspects to redevelop or create NI in arid areas. Most arid countries have found the same environmental conditions, particularly Middle Eastern countries, although they might have slightly different natural resources. However, the NI in arid areas has been strongly connected with two main planning aspects: planning strategies and irrigation systems. For the planning strategies, success will depend on recognizing NI as the basic and connecting layer of a spatial planning strategy. It is necessary to expand on traditional green space and recreation strategies, so as to include natural and environmental resources, as well as involve a wide spectrum of participants and ensure timely implementation. For the irrigation system, the development of the drainage and irrigation systems is the most important facet of GI projects in arid areas, especially in combination with distinctive topographic features. The irrigation system depends on recycling waste water (grey water), groundwater recharge and using special native plants.

\section{REFERENCES}

[1] Lyle, J.T., Archetypes in arid landscapes. Sustainable Landscape Design in Arid Climates. Aga Khan Trust for Culture: Geneva, pp. 26, 1996.

[2] Abdelhalim, A.I., Culture, environment, and sustainability: theoretical notes and reflections on a community park project in Cairo. Sustainable Landscape Design in Arid Climates. Aga Khan Trust for Culture: Geneva, pp. 49-61, 1996.

[3] Bashandy, S., The watercourses within the framework of system ideology themes for environmental and green corridors. Al-Azhar Engineering International Conference (AEIC), Al-Azhar University, pp. 26-42, 2003.

[4] Benedict, M.A. \& McMahon, E.T., Green Infrastructure for the 21st Century. The Conservation Fund: Arlington, VA, pp. 15, 2002.

[5] Milton Keynes \& South Midlands Sub Regional Strategy (MKSM), Annual monitoring report, Northamptonshire County Council Growth Management Team, 2006.

[6] ECOTEC City Region Green Infrastructure Strategic Planning. Raising the Quality of the North's City Region. Park Row, Leeds, UK, pp. 6-24, 2006.

[7] General Organization of Physical Planning (GOPP), Cairo future vision 2050. Ministry of Housing, General Organization of Physical Planning, Cairo, 2007.

[8] Barada, A., Steno, M., Tulan, N. \& Yousry, M., Master Plan of River Nile Banks of Greater Cairo. Faculty of Regional and Urban Planning, Cairo University, Cairo, pp. 28-40, 2005. 
[9] Mahmoud, N. \& Selman, P., Connecting natural infrastructure in spatial planning in arid zones. Ecological Networks: Science and Practice, 16th Annual Iale UK Conference, Edinburgh University, UK, pp. 97-104, 2009.

[10] Roberts, D., (1796-1864), Nilo Meter, available at http://www.museum-tours.com/museum/ roberts/roberts0.htm (accessed on 5 June 2010).

[11] Habitat International Coalition (HIC), Geziret Ed-Dahab Island, Cairo, Egypt: Inhabitants face expulsion to give way to private development projects, Framework of the Land Forum, Cairo, May 2009.

[12] Harris, M., Geziret Ed-Dahab Island, Cairo, Egypt: Inhabitants face expulsion to give way to private development projects under Cairo's intended urban master plan for 2050, The Egyptian Centre for Housing Rights (ECHR), Cairo, 2009.

[13] Mahmoud, N. \& Selman, P., Natural infrastructure in urban and planning strategies in arid zones: case studies from Egypt. The Sustainable City VI, Sixth International Conference on Urban Regeneration and Sustainability, A Coruna, Spain, 2010, available at http://library.witpress.com/pages/PaperInfo.asp?PaperID=20827 (accessed on 14 April 2010). WIT Transactions on Ecology and the Environment, Vol. 129.

[14] Raafat, A., EL-Sawy, A., Abdallah, A. \& Wageh, A., The Upgrading of Urban Environment and Preservation of Urban Character of Greater Cairo. Maadi Area. Cairo. The General Organization of Physical Planning: Cairo, pp. 9-20, 2005.

[15] Salama, A., Shaker, M. \& Abdalla, A., Management Plan for Wadi Degla Protected Area, Cairo. Egyptian Environmental Affairs Agency: Cairo, pp. 17-45, 2005.

[16] General Organization of Physical Planning (GOPP), The Development of Historic Places in Cairo, Ministry of Housing, Cairo, 2005. 